\title{
De sitiantes a moradores de vila: o projeto de integração do rio São Francisco com bacias hidrográficas do Nordeste brasileiro e as novas territorialidades
}

\section{From sitiantes to villagers: the integration project of the São Francisco river with hydrographic basins of the Brazilian Northeast and the new territorialities}

Verena Sevá Nogueira - Doutora em Antropologia, pela Universidade Estadual de Campinas (Unicamp). Professora adjunta da Unidade Acadêmica de Ciências Sociais da Universidade Federal de Campina Grande (UFCG). E-mail: verenaseva@gmail.com.

\section{Resumo}

O projeto de integração do rio São Francisco às bacias hidrográficas da região semiárida brasileira é uma grande e polêmica obra pública que, para muito além de seu escopo principal - o abastecimento de uma região carente de recursos hídricos, atinge uma população que vive e trabalha na área por ela impactada. Neste artigo analisamos os efeitos sociais desse projeto para um grupo de sitiantes do município de São José de Piranhas, no estado da Paraíba, que, em razão das obras da transposição, foi expropriado de suas terras e casas de morada, e posteriormente reassentado em vilas produtivas rurais, espaços projetados, construídos e regrados por uma diretriz governamental. Vilas que se desvelaram novos locais de vida e trabalho para as famílias que se depararam com novas paisagens, novas arquiteturas e novas formas de organização territorial que impactaram suas relações de trabalho, de moradia e de convivência social. Não obstante, observamos um processo de reconstrução territorial que tem início com a chegada das famílias nos reassentamentos, no qual passam a reelaborar esse novo e estranho lugar e a construir um novo território de pertencimento, a partir do acionamento de conhecimentos, saberes e técnicas trazidas da antiga vida nos Sítios.

\section{Palavras-chave}

Grandes Projetos. Desapropriação. Reassentamento. Novas Territorialidades. Famílias Rurais.

\begin{abstract}
The project to integrate the São Francisco river into the watersheds of the Brazilian semiarid region is a large and controversial public work that, beyond its main scope - supplying a region devoid of water resources, reaches a population that lives and works in the area impacted by it. In this article we analyze the social effects of this project for a group of small farms from the municipality of São José de Piranhas, in the state of Paraíba, which was expropriated from their lands and houses of residence and was subsequently resettled in productive villages rural areas, designed spaces, built and regulated by a governmental directive. Villages that unveiled new places of life and work for families who came across new landscapes, new architectures and new forms of territorial organization that affected their relationships of work, housing and social coexistence. Nevertheless, we observe a process of territorial construction that begins with the arrival of the families in the resettlements, in which they begin to rework this new and strange place and build in it a new territory of belonging. In order to do so, one can observe the activation of knowledge, knowledge and techniques brought from the old life in the Sítios.
\end{abstract}

\section{Keywords}

Large Public Works. Expropriation. Resettlement. New Territorialities. Rural Families 


\section{INTRODUÇÃO}

Nos anos de 2010 a 2013 um grupo aproximado de 250 famílias rurais do município de São José de Piranhas (Figura 1), no extremo oeste do estado da Paraíba, no Brasil, foi desapropriado de suas terras e casas em decorrência do Projeto de Integração do Rio São Francisco (PISF), obra do governo federal brasileiro que objetiva desviar as águas do principal rio da região Nordeste brasileira, o São Francisco, para o abastecimento de pequenas bacias hidrográficas que fornecem água para 390 municípios carentes de recursos hídricos.

Figura 1 - Localização do município de São José de Piranhas (PB)

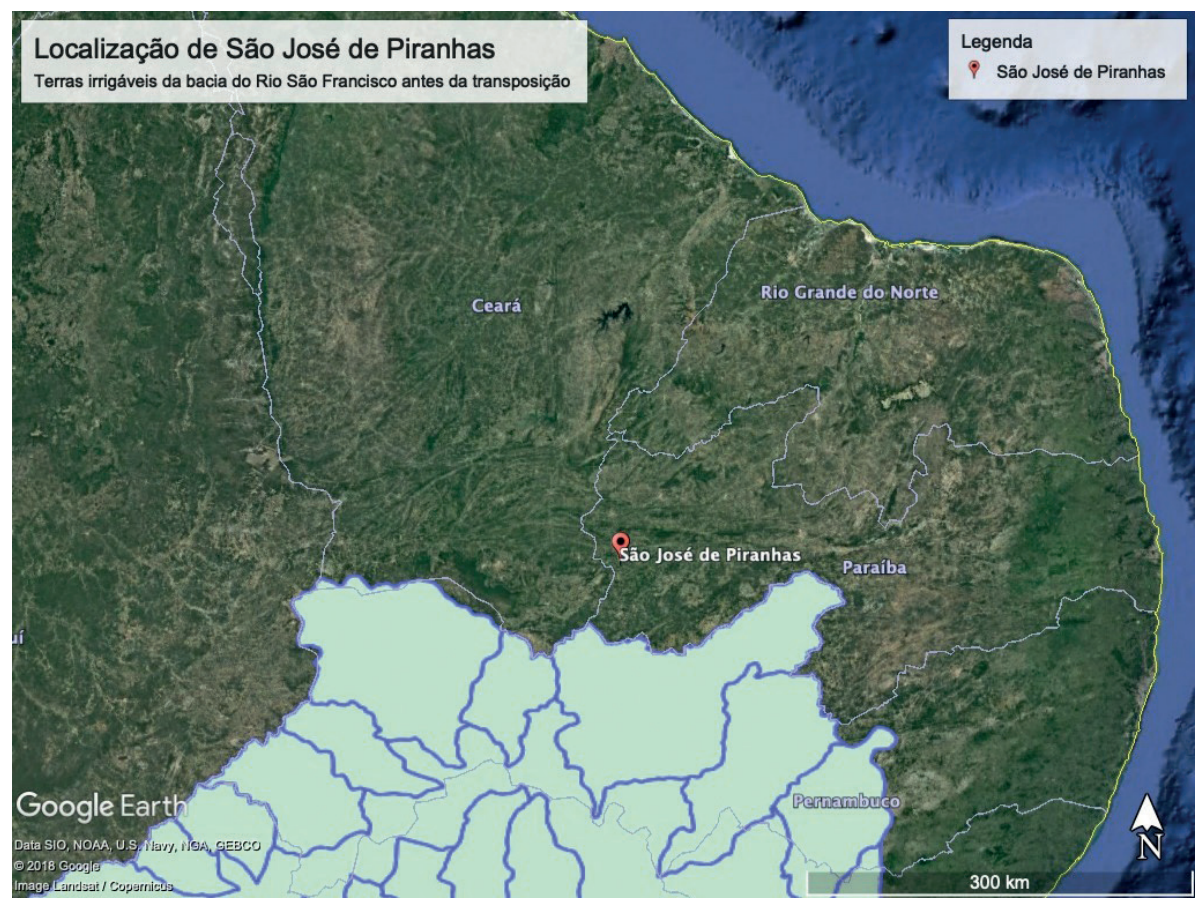

Fonte: Google Earth (2019).

O projeto de integração do rio São Francisco com bacias hidrográficas no Nordeste do Brasil é uma ideia antiga, remontando às primeiras décadas do século XIX, de quando se tem um primeiro registro documental, de autoria do padre carmelita João de Santa Rosa, enviado ao monarca D. João VI, do Reino Unido de Portugal, Algarve e Brasil, recomendando a seu filho, D. Pedro I, a realização de um estudo sobre a possibilidade da obra (LIMA, 2005). Contudo, foi somente no início da segunda metade do século XIX, ainda durante o Império, que nasceu a ideia oficial de transposição e integração do rio São Francisco. A 
Comissão Científica de Exploração chefiada pelo engenheiro e físico brasileiro Guilherme Schuch de Capanema, o Barão de Capanema, propôs a construção de açudes e a integração do rio São Francisco com os rios do Nordeste setentrional. Porém, uma proposta que resultou apenas na construção do primeiro açude no Ceará, o de Quixadá.

Desde o século XIX, e ao longo do XX, a ideia do rio São Francisco como um "rio de união nacional" figura no imaginário social brasileiro. Em 1958, o engenheiro Mário Ferracuti publica na revista "O Cruzeiro" seu projeto de construção de uma barragem para represamento das águas do rio São Francisco nas proximidades de Cabrobó, PE, com a finalidade de bombear água para os estados do Ceará e do Rio Grande do Norte. Mais tarde, no início da década de 1980, a ideia de transpor as águas do São Francisco reaparece na cena governamental como salvação para a seca nordestina, mas novamente não avança para além do Plano de Irrigação do semiárido, no âmbito do Departamento Nacional de Obras de Saneamento (DNOS).

No início dos anos 1990 o então ministro do governo Itamar Franco e ex-governador do Rio Grande do Norte, Aluísio Alves, resgata a discussão do abastecimento do Nordeste e apresenta um novo projeto de transposição do rio São Francisco, mas o Tribunal de Contas da União não o aprova. Um pouco mais tarde, no primeiro governo de Fernando Henrique Cardoso, no ano de 1994, o referido projeto volta à cena política com a apresentação de nova versão que passa a incluir o estado da Paraíba como receptor das águas transpostas; novamente é abandonado.

No início do primeiro governo do presidente Luís Inácio Lula da Silva, em 2004, são retomadas as discussões sobre o projeto da transposição que, em meio a muito alarde e polêmicas nos campos econômico, político e ambiental, é finalmente aprovado no ano seguinte, pelo Conselho de Recursos Hídricos. Ato contínuo, em 2006, o Instituto Brasileiro do Meio Ambiente e dos Recursos Naturais Renováveis (IBAMA) concede ao Ministério da Integração Nacional (MIN) licença prévia para o início do projeto, que é incorporado ao Plano de Aceleração de Crescimento (PAC); e, em 2007, é finalmente expedida a licença para a instalação do projeto.

O projeto de integração da bacia do rio São Francisco com rios do Nordeste Setentrional ${ }^{1}$ é uma obra pública sob responsabilidade do Ministério da Integração Nacional que teve início em 2007, estando atualmente em fase final de implantação em seu eixo Norte. Uma grande obra pública, com

\footnotetext{
Localmente essa obra é nomeada como projeto de transposição, ou simplesmente transposição do rio São Francisco, como passo a denominá-la a partir desse ponto da escrita.
} 
477 quilômetros de extensão, que atravessa quatro estados da federação, Pernambuco, Paraíba, Ceará e Rio Grande do Norte, provocando mudanças socioterritoriais de uma magnitude ímpar, atingindo populações que vivem nos locais das obras e em seu entorno.

Para além dos aspectos de cunho econômico e ambiental presentes nas discussões sobre os efeitos e consequências das grandes obras públicas ${ }^{2}$, este artigo se insere num debate sobre os impactos sociais sofridos pelas populações atingidas, especialmente por uma camada subalterna da sociedade rural sertaneja, como populações camponesas (GONÇALVES, 2014; NOGUEIRA, 2010; NASCIMENTO, 2018) e os grupos indígenas (CAMARGO, 2017), historicamente menosprezada nos projetos de desenvolvimento econômico, que costumam justificar os perversos "efeitos sociais" sofridos pelas populações impactadas como o preço que devem arcar em prol de um desenvolvimento social e econômico mais amplo (SIGAUD, 1988).

Neste debate, objetivamos refletir sobre os efeitos socioterritoriais da desapropriação e do posterior reassentamento de famílias sitiantes do município paraibano de São José de Piranhas, provocados pelas obras da transposição do rio São Francisco.

\section{DE SITIANTES A DESAPROPRIADOS}

As famílias que tiveram suas terras e casas desapropriadas em São José de Piranhas em razão do projeto de transposição do rio São Francisco constituem uma população rural formada por sitiantes, que moravam e trabalhavam na porção oeste do município, próxima à divisa com o estado do Ceará ${ }^{3}$.

\subsection{SÍTIO: UM TERRITÓRIO TRADICIONAL CAMPONÊS}

Sítio é uma categoria territorial e identitária comum no Nordeste rural brasileiro. Um território que se configura como espaço das relações sociais de famílias rurais, formado pela inextricável composição de uma dimensão material ou corpórea, perfilada como espaço de poder, organização fundiária, moradia, trabalho, sociabilidade e reprodução, com uma dimensão das representações simbólicas que se tem desse espaço como lugar de pertencimento e identidade.

\footnotetext{
A respeito desse tema, ver IPEA (2010).

Além dessas famílias de pequenos proprietários de terra e moradores (que compõem a categoria dos sitiantes), a desapropriação atingiu, ainda, alguns médios e grandes proprietários de terra que, contudo, não serão tratados neste artigo, uma vez que não participam dos processos de reassentamento em questão.
} 
Território e territorialidades são conceitos centrais para o entendimento das configurações socioterritoriais dos grupos humanos. A definição de território varia, todavia, em relação às diferentes perspectivas acionadas dentro do binômio materialismo-idealismo, que priorizam, respectivamente, sua dimensão físicomaterial e sua dimensão simbólico-ideal.

Numa perspectiva que podemos classificar de materialista, Raffestin (1983) concebe o território como fruto da ação humana projetada num espaço, pois ao "se apropriar de um espaço, concreta ou abstratamente (por exemplo, pela representação), o ator 'territorializa' o espaço” (RAFFESTIN, 1983, p. 143). Uma noção que remete à ideia de espaço a priori e de território como resultado, concebido numa relação entre espaço e humanos, sendo impossível, dessa forma, pensar território sem a interação das relações sociais daqueles que o praticam.

José Luís García (1976 apud HAESBAERT, 2004), por contraponto, defende precipuamente um caráter subjetivo (simbólico-cultural) de território, como uma ideia que se interpõe entre o meio físico e o homem. Afirma o autor que "a semantização do território pode explicar-se parcialmente a partir do meio, mas a investigação do meio físico nunca nos permitirá concluir que deve dar-se um tipo determinado de semantização" (GARCIA, 1976, p. 52 apud HAESBAERT, 2004, p. 70).

Sem a pretensão de um aprofundamento teórico desse debate, tomaremos por base teórica-metodológica uma perspectiva "integradora" de território como um espaço que não pode ser considerado estritamente natural, político ou econômico, ou como uma representação desconectada de uma base material, mas que deve consistir no entrelaçamento dessas dimensões, ou, nas palavras de Haesbaert (2004), território como "fruto da interação entre relações sociais e controle do/pelo espaço, relações de poder em sentido amplo, ao mesmo tempo de forma mais concreta [...] e mais simbólica [...]” (HAESBAERT, 2004, p. 235).

Ademais, quando destacada a variável temporal, teríamos aí um processo de ocupação e uma noção de território indissociável da de territorialidade, entendida como processo de construção territorial ou "pressuposto geral para a formação de territórios" (HAESBAERT, 2004, p. 36), e não apenas como dimensão simbólico-identitária do território. Territorialidade ou territorialidades, no plural, que envolvem

a ligação a lugares precisos, resultando de um longo investimento material e simbólico e que se exprime por um sistema de representações, de um lado, e, de outro lado, os princípios da organização - a distribuição e os arranjos dos lugares de morada, de trabalho, de celebrações, as hierarquias sociais, as relações com os grupos vizinhos (GODOI, 2014, p. 444). 
Em outras palavras, defendemos a dimensão processual de territorialidade e, como decorrência, o caráter plástico do território, em constante conformação pela ação humana.

Pontuadas essas concepções teórico-metodológicas sobre território e territorialidades, passamos a refletir acerca da configuração socioterritorial preexistente nas áreas atingidas pelas obras da transposição em São José de Piranhas: os Sítios, porções indivisíveis de terra, no interior das quais famílias nucleares detêm e se organizam territorialmente em parcelas de terra em separado. Outrossim, um Sítio é um espaço onde operam relações de vicinalidades ${ }^{4}$ (PINACABRAL, 2014) e de interconhecimento entre seus habitantes, que se identificam como pertencentes física e moralmente àquele lugar.

O mais populoso Sítio desapropriado em São José de Piranhas foi assim descrito:

O Sítio Riacho da Boa Vista era composto por pequenos sítios ocupados por famílias nucleares que dividiam esses espaços entre si [...]. A cada família nuclear, correspondia um chão de casa dentro do sítio. O chão de casa era formado pelo conjunto terreiro-casa-quintal, cada quintal com sua horta, seu galinheiro, seu chiqueiro e suas fruteiras. Cada terreiro com suas plantas e arvores. Esse era um espaço predominantemente feminino, cabe à mãe de família e as filhas solteiras o cuidado dos animais, da horta e da casa. A roça, por sua vez, era o espaço particularmente masculino, de responsabilidade do pai de família (NASCIMENTO, 2018, p. 40).

A partir de pesquisas realizadas em contextos camponeses nordestinos, Ellen Woortmann (1995) distingue três sentidos costumeiramente atribuídos ao vocábulo sítio. Um primeiro refere-se ao local onde se localiza o conjunto casa-quintal no interior das terras de famílias camponesas. Um segundo abarca o conjunto casa-quintal, considerado um espaço feminino, e os espaços de roça e de mato, o espaço masculino ${ }^{5}$. Já um terceiro sentido, grafado pela autora com um "S" inicial maiúsculo, nomeia conjuntos de sítios, na segunda acepção exposta (parcelas familiares), nos quais seus moradores, além de vizinhos estão relacionados por relações de parentesco, formando um "território de parentesco" " (WOORTMANN, 1995).

4 Diferentemente da noção de vizinhança, remetida exclusivamente à dimensão espacial de domicílios dispostos proximamente, vicinalidade refere-se às relações afetivas e de lealdade constituídas e constitutivas numa situação de moradia contígua e/ou próxima.

5 Sobre uma discussão sobre espaços femininos e masculinos em áreas rurais, ver também Heredia (1979).

6 A configuração socioterritorial dos sitiantes desapropriados em São José de Piranhas assemelhase a esta terceira acepção da palavra sítio, descrita por Woortmann (1995), e, por isso, minha opção por grafá-la analogamente como a inicial maiúscula. 
A origem de um Sítio está muitas vezes associada ao apossamento de uma área por ancestral comum do grupo, o chefe de uma parentela, que adentra e se fixa na terra de diversas maneiras: por conquista, doação ou compra-e-venda. Uma terra familiar que, com o crescimento vegetativo do grupo pela constituição de novos núcleos familiares através do casamento, passa por sucessivas partilhas que levam à sua subdivisão em pequenas áreas ou lotes ${ }^{7}$. Não obstante às sucessivas subdivisões, formais ou informais de um Sítio, a totalidade de sua área continua a compor um grande território de parentes, ligados não apenas pela proximidade territorial, mas por laços de parentesco, interconhecimento, tradições e saberes em comum (GODOI, 1999).

Por fim, destacamos na configuração dos Sítios de São José de Piranhas uma prática tradicional de moradia no campo - ainda presentes em muitos contextos rurais brasileiros - e enfeixadas no que concebe a literatura socioantropológica como "sistema de morada".

Em um "sistema de morada" o proprietário cede um pedaço de terra (e algumas vezes também uma casa, se ali houver) para uma família nuclear ${ }^{8}$ fixar morada, plantar e ter sua criação ${ }^{9}$. Em troca, a família moradora ${ }^{10}$ se obriga a trabalhar parte do tempo nas terras do dono da terra ou a dar a ele parte do que produz. Os "sistemas de morada" configuram-se a partir de uma heterogeneidade de situações empíricas, como o descrito dos engenhos da zona da mata nordestina de finais do século XIX até os anos 1960, quando ocorreu a entrada efetiva dos direitos trabalhistas no campo ${ }^{11}$. Um sistema de morada tecido em meio a relações de trocas pessoais fortemente hierarquizadas entre os senhores de engenho e seus moradores (PALMEIRA, 1977; GARCIA JÚNIOR, 1983; SIGAUD, 2004; TEIXEIRA, 2014).

Nos Sítios atingidos em São José de Piranhas, o "sistema de morada" configurava-se a partir de dois modelos principais. Numa primeira

\footnotetext{
Observa-se que nos Sítios nordestinos, como em vários outros contextos camponeses, a partilha da terra é realizada "de boca", sem a devida formalização e registro da transmissão da terra. Essa foi a situação encontrada nas áreas desapropriadas e, por isso, antes do processo de desapropriação-indenização dos seus habitantes, foi necessária a regularização fundiária de grande parte da área. Sobre esse tema, ver Nogueira (2015).

8 A unidade residencial (casa de morada) é costumeiramente o lugar de moradia de uma família nuclear, composto basicamente por um casal, seus filhos solteiros e algum parente eventual.

9 Criação é como se conhece o conjunto dos animais criados nas proximidades da casa, como galinhas, patos, porcos e, eventualmente, uma cabra ou uma vaca.

10 Assinalo que o uso do itálico é indicativo da transcrição no texto de palavras, expressões e frases mencionadas por interlocutores de pesquisa.

11 A extensão dos direitos trabalhistas aos trabalhadores rurais gerou a saída de muitos trabalhadores que moravam no interior de grandes e médias fazendas brasileiras. Isso porque as leis tiveram como um de seus efeitos secundários a quebra das relações pessoais necessárias à continuidade das relações de morada. A lei a que me refiro é o Estatuto dos Trabalhadores Rurais, Lei no 4214/1963 (BRASIL, 1963).
} 
situação, semelhante ao descrito acima para os engenhos de cana de açúcar pernambucanos, as famílias moravam e trabalhavam nas terras do dono da terra em troca de um pequeno sítio (parcela de terra) para morar e cultivar seu sustento; uma segunda modalidade era a das famílias que, embora destituídas da propriedade da terra, possuíam um chão de casa, ou seja, eram donas de uma casa localizada na terra de outrem, normalmente dos pais de um dos cônjuges ou de algum parente próximo ${ }^{12}$.

Um "sistema de morada" que, se de um lado expressava e mantinha uma situação hierárquica entre aqueles que tinham o domínio da terra e aqueles que dependiam da terra de um vizinho para trabalhar e morar, por outro lado, alicerçava-se em relações de proximidade sociocultural existente entre as famílias de moradores e as dos donos das terras, muitas vezes parentes consanguíneos, por afinidade ou por compadrio. Uma proximidade, ademais, que guarda relação com vários arranjos socioterritoriais historicamente praticados por essa população, como a concessão dos pais a seus filhos, por ocasião do casamento, de um lugar em suas terras para fixarem sua nova unidade residencial (um chão de morada) e constituírem ali um novo núcleo familiar. Uma estratégia comumente verificada em vários contextos camponeses, caracterizados corriqueiramente pela escassez de terras, nos quais os novos casais, por não disporem de terra para fixar suas novas unidades residenciais, tornam-se moradores de seus pais ou de algum parente próximo, ou mesmo de um vizinho, até obterem recursos necessários para a compra de suas próprias terras, ou até decidirem sair do campo e se fixarem nas cidades em busca de uma outra forma de vida (HEREDIA, 1979; WOORTMANN, 1995; GODOI, 1999; NOGUEIRA, 2010).

\subsection{A SAÍDA DOS SÍTIOS}

Expedidos os mandados desapropriatórios, nos anos de 2009 a 2012, o processo de desocupação dos Sítios deu-se em etapas, de acordo com as necessidades da empresa de fazer as obras As primeiras a sair foram as famílias que tinham seus Sítios na área atingida pelas obras do grande açude de Boa Vista. Na sequência, as famílias que habitavam as áreas destinadas à construção das três primeiras vilas para o reassentamento das famílias. Por fim, saíram aquelas que estavam na área onde tardiamente foi definida a construção da quarta vila. A desapropriação atingiu uma grande área da porção oeste do município, entre duas grandes serras.

12 O domínio da casa resultava de uma transação de compra e venda ou da construção do imóvel pela família dos moradores. 
Na implementação do processo de desapropriação de terras em São José de Piranhas, o Ministério da Integração Nacional (MIN) contratou uma empresa privada, Geosolos, responsável pela realização da perícia e da avaliação das terras, das casas e demais benfeitorias (cercas, poços, lavouras, árvores frutíferas e pequenos açudes). Na sequência, o Departamento Nacional de Obras Contra as Secas (DENOCS), órgão do MIN, expediu laudos com os valores indenizatórios a serem pagos aos sitiantes.

A diferenciação das famílias em proprietárias de terra ou moradoras foi central para a formalização do processo estatal de desapropriação, especialmente no que tange às modalidades e aos valores indenizatórios. Uma primeira situação era a das famílias proprietárias da terra e/ou casa (com chão de casa). Para essas, quando a soma do valor da terra e/ou casa, acrescido do das benfeitorias, era inferior a 30 mil reais à época do pagamento da indenização, havia duas opções: receber a indenização total (pela terra e/ou casa, acrescidos das benfeitorias) ou receber apenas uma indenização parcial (pela terra e benfeitorias no caso dos proprietários de terra, ou pelas benfeitorias para os moradores com chão de casa), tornando-se sujeitos de direito de um lote de terra numa das vilas produtivas rurais (vilas) a serem construídas no bojo do projeto de transposição. Já uma segunda situação era a das famílias de moradores destituídas de chão de casa, cuja única opção era a saída do Sítio e a espera do reassentamento numa das futuras vilas.

Ademais, durante o tempo da espera do reassentamento nas vilas, as famílias desapropriadas que optaram por permutar suas casas - a parte majoritária - foram inscritas num Programa de Transferência Temporária (PTT), por meio do qual recebiam um aluguel de 1,5 salários mínimos ao mês, para morarem e manterem suas necessidades básicas, durante o período entre a saída dos Sítios e o ingresso como reassentados na vila ${ }^{13}$. Tratou-se de um "benefício" a que tiveram acesso depois de uma negociação protagonizada e mediada pelo sindicato dos trabalhadores do município, importante mediador desde o início do processo da desapropriação ${ }^{14}$.

A saída das famílias desapropriadas de suas terras (Sítios), com seu posterior reassentamento numa das vilas produtivas rurais, caracteriza-se como um processo de territorialização (OLIVEIRA, 2016), ou mais especificamente, um processo de des-reterritorialização (HAESBAERT, 2004).

13 Sobre o processo vivenciado pelas famílias desapropriadas no período intermediário entre a saída do Sítio e o reassentamento nas vilas, ver Nogueira (2015).

14 Note-se que o Movimento dos Atingidos por Barragens (MAB), importante movimento social brasileiro na luta dos direitos das populações atingidas por alagamentos provocados pela construção de barragens, não está presente no contexto estudado, tendo ficado a cargo do Sindicato dos Trabalhadores Rurais do município o protagonismo da defesa das famílias expropriadas pela transposição. As razões da não atuação do MAB no local merecem ser investigadas. 
A partir do estudo com povos indígenas, Oliveira (2016) define territorialização como

um processo de reorganização social que implica: 1) a criação de uma nova unidade sociocultural mediante o estabelecimento de uma identidade étnica diferenciadora; 2) a constituição de mecanismos políticos especializados; 3) a redefinição do controle social sobre os recursos ambientais; 4) a reelaboração da cultura e da relação com o passado (OLIVEIRA, 2016, p. 203).

Embora não estejamos tratando de um processo de territorialização de grupos indígenas, tampouco preocupados com a dimensão étnica do grupo estudado, entendemos que uma leitura abrangente dessa definição é iluminadora para analisarmos o processo de desapropriação e reassentamento das famílias afetadas pelas obras de transposição.

Por desterritorialização entendemos a "perda do território" por um grupo, no sentido de perda ou limitação do controle de sua territorialidade num dado espaço físico e/ou simbólico. E por reterritorialização a (re)tomada pelo grupo do controle de sua territorialidade como agente ativo da construção social de seu território (HAESBAERT, 2004). Noções centrais, portanto, para pensarmos o processo de desapropriação das famílias afetadas (desterritorialização) e seu subsequente reassentamento nas vilas, a partir das novas territorialidades negociadas e reelaboradas no novo lugar (reterritorialização).

Um processo de desterritorialização das famílias desapropriadas de São José de Piranhas teve início antes mesmo de suas saídas dos Sítios, em decorrência dos efeitos gerados pela expedição dos laudos expropriatórios: interdição de plantar em suas terras nem mais um pé de planta, e ordem para retirada das cercas de arame farpado que continham suas poucas cabeças de gado. E, quando recebesse o primeiro pagamento [o primeiro alugued, tinha que derrubar a casa e sair do Sítio ${ }^{15}$.

Desde os Sítios, o destino imediato das famílias mostrou uma pequena variação. As estratégias de moradia mais comuns foram alugar casa no campo ou cidade, ou mudar para imóvel cedido no Sítio de algum parente. Algumas famílias, ademais, optaram pela moradia em Boa Vista (Distrito de Boa Vista) ${ }^{16}$, povoado próximo à área desapropriada mais populosa, o Sítio Riacho da Boa Vista. Num segundo momento, algumas famílias puderam, graças ao ingresso monetário do

15 Aluguel é como localmente denominam o benefício do PTT. Uma verba recebida mensalmente e destinada à moradia e manutenção das famílias expropriadas de suas terras e casas.

16 O Distrito de Boa Vista é uma terra da Igreja de São João Batista, imerso na área desapropriada, que pela concentração de moradores (antes da chegada dos desapropriados havia cerca de 100 casas construídas lado a lado na única rua que havia no local) e, principalmente por sua condição jurídico-territorial, entendo recaia a razão de ter ficado fora do processo desapropriatório. 
aluguel mensal do governo (PT'T), adquirir um pequeno lote no campo ou na Boa Vista e construir casas de moradia, onde viveram até o reassentamento nas vilas.

A pesquisa etnográfica teve início em 2013, momento em que apenas uma família ainda permanecia na área desapropriada ${ }^{17}$. Dentre os inúmeros questionamentos gerados no campo, o destino do gado foi um deles. Inquiridos sobre o que fizeram com o gado depois da desapropriação, os sitiantes diziam [o gado] tá solto por aí. Uma representante do sindicado local afirmou que os grandes proprietários tiraram a cerca e daí a bagunça começou. As cercas separavam as terras dos grandes proprietários e as dos pequenos, e cercavam o gado para que não adentrasse nas lavouras.

Aquele estar solto que, literalmente, expressa não estar mais no cercado da família. Não obstante, uma expressão que descreve diferentes alternativas acionadas pelas mesmas para lidar com o gado: venda dos animais, envio dos mesmos para cercados (terras) de parentes ou, ainda, sua soltura nas terras do governo.

A totalidade da área desapropriada no município, que passou a domínio da União, pode ser classificada e dividida em relação aos seus diferentes destinos e usos: canteiros das obras da transposição propriamente ditas (os canais de água, o grande açude de Boa Vista e os túneis), o entorno do açude de Boa Vista (porções de terra ainda não inundadas e áreas de proteção da barragem), áreas de proteção ambiental, e terrenos onde foram construídas as vilas produtivas rurais. Nessa grande área desapropriada, terra do governo é a denominação êmica das parcelas de terra que permanecem vaz̧ias na concepção da população das cercanias, as terras do entorno do açude e as terras de proteção ambiental, e onde se verifica a soltura do gado.

Embora apareça como uma das alternativas escolhidas pelas famílias desapropriadas para lidarem com o gado, a criação do gado solto não era uma prática até então observada no local, diferentemente de outros contextos rurais brasileiros, onde a criação de gado, bovino ou caprino, é realizada em terras de uso comum, como encontrado nas comunidades de fundo de pasto do sertão da Bahia (CARVALHO, 2016) e nos faxinais do norte do Paraná (ALMEIDA; SOUZA, 2009), para citar alguns dos principais exemplos descritos na literatura brasileira. Soltar o gado, nesse sentido, remete a um alargamento espacial da relação dos sitiantes com o gado e com o espaço físico percorrido pelos animais, modificando um sistema tradicional de criação de gado na área estudada.

${ }_{17}$ Trata-se de uma família que optou em receber a indenização total e não ir para as vilas, pois precisava de dinheiro para um tratamento médico da filha em São Paulo. Mais tarde, chegado o momento de sair do Sítio, como não tinha mais recursos para comprar outra terra, já que gastara tudo com o tratamento da filha, a família ali permaneceu até quanto pode, saindo de lá apenas quando obteve excepcionalmente o direito ir para uma das vilas. 
Ao perscrutarmos a organização e as práticas socioterritoriais das famílias sitiantes antes do processo desapropriatório, verificamos que algumas famílias tinham uma pequena quantidade de reses criadas no cercado da terra familiar e em pastos alugados ou emprestados, perfazendo em muitas situações um rodízio de terra em busca de pastagem durante o período das secas. Ao saírem dos Sítios, as famílias que mantiveram algum gado optaram por levá-lo para outras terras, normalmente de parentes próximos, ou pela soltura dos animais nas terras do governo. Nessas terras também há animais de criadores que não foram alvo de processo de desapropriação de terras, mas que viram nessa área vaz̧ia um local a mais para engordar seu gado. Há situações, inclusive, de animais trazidos do estado vizinho, o Ceará, como é o caso de um grande fazendeiro de gado, que com o valor da indenização recebida pela desapropriação de suas terras na Paraíba, comprou outra fazenda no Ceará, e atualmente utiliza tanto as terras da nova propriedade cearense, como as terras do governo para criar seu gado ${ }^{18}$.

\section{DE SITIANTES A MORADORES DE VILA}

No ano de 2016 ocorreu o reassentamento das famílias desapropriadas numa das quatro vilas produtivas rurais construídas no município de São José de Piranhas. O direito ao reassentamento resultou, como mencionado anteriormente, de um acordo indenizatório entre o Ministério da Integração Nacional e as famílias desapropriadas, com mediação do Sindicato dos Trabalhadores Rurais de São José de Piranhas. No total, foram reassentadas 227 famílias que, à época do recebimento da indenização, optaram por permutar suas casas de morada por uma casa e um lote de trabalho numa das vilas a serem construídas. As famílias reassentadas correspondem à maioria da população desapropriada pelas obras da transposição no município, composta por pequenos proprietários de terra e por moradores, com ou sem chão de casa. ${ }^{19}$ Nesse processo, a distribuição das famílias nas quatro vilas (Irapuá 1 e 2, Quixeramobim e Cacaré) foi balizada pelos seguintes critérios: lugar de origem, relações de parentesco e tamanho da área

$\overline{18}$ A prática da criação de gado solto como um sistema socioterritorial mais amplo é um tema que analiso ainda de forma preliminar no paper "Vilas produtivas rurais e 'terras do governo': reassentamento de famílias rurais atingidas por obras da transposição do rio São Francisco", apresentado na $31^{a}$ Reunião da Associação Brasileira de Antropologia (NOGUEIRA, 2018).

19 No caso das famílias que tinham a propriedade legal de uma pequena área de terra ou de um chão de casa, a opção pela permuta da casa é explicada pelo fato de que o valor da indenização pela terra e/ou pela casa não era suficiente para comprar uma outra terra e/ou pela casa num outro local; já para as famílias destituídas de terra e de chão de casa, a ida para as vilas produtivas rurais aparecia como a única opção. 
territorial de cada vila. Foram reassentadas 30 famílias na Vila Irapuá 1, 20 na Irapuá 2, 47 na Quixeramobim e 130 na vila Cacaré.

Nesta análise, o olhar recai sobre o processo de reassentamento ocorrido na vila produtiva rural Cacaré, que contou com um projeto arquitetônico análogo às outras 17 vilas produtivas rurais construídas pelo Ministério da Integração Nacional no bojo das obras da transposição ${ }^{20}$. Estamos falando de vilas que encerram um novo formato socioterritorial ao qual as famílias foram submetidas a partir de um processo de territorialização (OLIVEIRA, 2016) deflagrado por ações de uma instância político administrativa externa ao grupo levantamento da área, demarcação, expedição de laudo expropriatório e retirada da população, elaboração de projeto arquitetônico e reassentamento - que vêm sendo reelaboradas pelas famílias no seu cotidiano, a partir do acionamento de conhecimentos e práticas tradicionais, e com a mediação do Sindicato dos Trabalhadores Rurais de São José de Piranhas e da Associação dos futuros moradores da Vila Jurema (depois Cararé) ${ }^{21}$, a partir de 2015.

Por meio dessas reelaborações, as famílias apõem resistência ao processo de desapropriação-reassentamento e, ao mesmo tempo, interagem com a nova e nem sempre querida - vida na Vila.

A população reassentada na vila Cacaré compõe-se majoritariamente por famílias de sitiantes: pequenos proprietários ${ }^{22}$ e moradores. No tempo do Sítio, seu cotidiano de trabalho consistia na agricultura "de aprovisionamento" 23 , com destaque para o plantio de milho, feijão e fava, além de verduras, ervas medicinais, legumes e alguns pés de fruta. No quintal das casas havia, costumeiramente, uma pequena criação de aves e alguns suínos. Com menor incidência havia a criação de gado bovino e caprino realizado por algumas famílias que possuíam uma área maior de terra.

As pequenas lavouras dos sitiantes, conhecidas como roças, eram majoritariamente cultivadas em terras das redondezas pertencentes a médios e grandes proprietários, pois as áreas de terra que possuíam eram insuficientes para a tradicional roça de coivara que costumavam fazer - prática agrícola tradicional

20 As 18 vilas produtivas rurais encontram-se distribuídas nos estados de Pernambuco, Ceará e Paraíba.

21 Inicialmente o nome da vila, constante do projeto do governo, era Jurema; contudo, foi modificado para Cacaré, depois de uma demanda dos seus futuros moradores, por entenderem que a área da Vila coincidia com um anterior Sítio que ali existia antes da desapropriação, o Sítio Cacaré.

22 A área das famílias desapropriadas variava entre 1 a 3 tarefas de terra. Uma tarefa nessa região mede $55 \times 55$ metros ou 0,3 hectares.

23 Em consonância com o que escreveu Sahlins (1970), a escolha da categoria agricultura "de aprovisionamento" abrange não apenas uma produção para o consumo direto (agricultura de subsistência), mas ainda uma modalidade de produção/economia agrícola que as famílias podem usar como moeda de troca para aquisição de outros bens de consumo direto. 
que consistia em desmatar o terreno com uma enxada, atear fogo no restante e, sob a fuligens, fazer o plantio. Um sistema caracterizado pelo rodízio de terras, no qual a cada ano a roça mudava de lugar, deixando a área do ano anterior em estado de pousio (descanso) até que a vegetação se recompusesse e o ciclo limpeza, queima e plantio reiniciasse.

A utilização das terras de outrem operava comumente por meio do contrato de parceria, que se iniciava com a solicitação pelo sitiante do lote de terra a ser cultivado naquele ano. Aceita a oferta, o sitiante limpava o terreno (cortava o mato grande), queimava o restante, plantava e aguardava uma boa chuva. Realizada a colheita, uma quarta parte da produção era destinada ao proprietário da terra, além da palhada que servia de alimento ao seu gado. Havia variações nesse sistema, mas, grosso modo, assim funcionava.

$\mathrm{Na}$ trajetória dessas famílias merecem destaque, ademais, a migração temporária para o trabalho na colheita da cana-de-açúcar na região Sudeste, um movimento migratório muito forte na região até a primeira década do século XXI (MENEZES, 1985; COVER, 2011), e a furadinha, uma nova modalidade de deslocamento migratório caracterizado pelo comércio a prazo de roupas nos estados do Piauí, do Pará e do Maranhão.

Findo o tempo do Sítio, a mudança das famílias para as vilas vem a implicar em significativas mudanças nas relações com seus espaços de vida (território). Nesse processo, focalizo dois elementos socioespaciais que se entrelaçam na conformação das novas territorialidades das famílias assentadas: a localização geográfica da vila Cacaré e a origem espacial de seus moradores; uma noção de territorialidade que, ademais da polissemia do termo em diferentes enfoques acadêmicos, está a reportar "processos de construção de territórios, isto é, de apropriação, controle, uso e atribuição de significados - não necessariamente nessa ordem - sobre uma parcela do espaço que é transformado em território" (GODOI, 2014, p. 444).

Por conseguinte, uma noção de território que não se esgota num espaço físico, pois não há território externo às relações sociais nele inscritas pelos que com ele se relacionam (HAESBAERT, 2004).

A vila Cacaré está localizada parcialmente onde antes havia um Sítio de mesmo nome. Nessa vila foram reassentadas famílias provenientes tanto do Sítio Cacaré como de outros das cercanias, como dos Sítios Anta, Canal, Ameixa e Santa Luzia ${ }^{24}$. Essa aparente coincidência ou proximidade entre lugares de

24 Observou-se que durante a construção da vila seus limites territoriais foram expandidos para permitir o reassentamento de um maior número de moradores do antigo Sítio Cacaré e de Sítios avizinhados. 
origem e destino verificada no reassentamento das famílias da vila Cacaré repetiuse nas outras vilas do município. Ressalte-se, entretanto, que esse modelo de reassentamento resultou de um acordo firmado entre o Ministério da Integração Nacional e o Sindicato dos Trabalhadores Rurais para a definição da vila em que cada família seria reassentada, baseado no critério básico da proximidade entre a vila e o Sítio de origem, como uma tentativa de ameninar os efeitos perversos desse deslocamento forçado.

Essa proximidade do antigo Sítio Cacaré com a atual vila Cacaré teve implicação no nome da vila. No projeto inicial proposto pelo Ministério da Integração Nacional o nome da vila era Jurema, pois, segundo relato de campo, um técnico do governo ao fazer medições no local teria abordado um sitiante e este teria lhe dito que ali era o Sítio Jurema, ficando assim inicialmente batizada o local. Menos de um ano do ingresso dos reassentados na vila, eles, já organizados numa associação recém-fundada - a então Associação dos futuros moradores da vila produtiva rural Jurema -, demandaram a mudança do nome para vila produtiva rural Cacaré, alegando que nessa vila seriam reassentadas, principalmente, as famílias moradoras do antigo Sítio Cacaré, o mais populoso das imediações, e de outros Sítios menores que com ele divisavam e guardavam relações de parentesco e interconhecimento.

Uma etapa subsequente do processo de reassentamento consistiu na escolha pelas famílias dos lotes residenciais que viriam a ocupar no interior das vilas, o que combinava dois critérios: sorteio e relações de parentesco. Em reuniões promovidas pelo Ministério da Integração Nacional, os futuros moradores das vilas deviam participar de um sorteio através do qual cada família, seguindo a ordem em que eram sorteadas, podia escolher um lote residencial e, ato contínuo, chamar para ocupar as casas vizinhas, outros 5 núcleos familiares aparentados dentro das linhas ascendentes, descendentes e colaterais até o primeiro grau, ou seja, pais, filhos e irmãos.

\section{AGORA A GENTE VIVE EM CONDOMÍNIO}

Nos meses de março e abril de 2016, 120 famílias foram reassentadas na vila produtiva Cacaré, ou simplesmente vila Cacaré como é localmente chamada - um novo lugar onde as famílias foram colocadas e com o qual estão se relacionando e construindo um novo território.

A configuração espacial da vila está organizada numa composição de duas áreas distintas: o setor residencial e as terras de trabalho (ou de sequeiro). No setor residencial encontram-se os lotes residenciais, medindo 50 metros de 
frente por 100 de fundos, com uma casa de morada no seu interior, e as áreas de uso coletivo. Nestas estão o prédio da associação local e o posto de saúde (ainda inativo), a praça central com alguns brinquedos de parque infantil e as áreas (ainda) vazias, como um terreno já demarcado para a construção da capela do padroeiro da Vila, São Francisco de Assis. Nesse primeiro setor há também as áreas de preservação ambiental, uma estação de tratamento de água, as ruas e os lotes de reserva para futuros assentados ${ }^{25}$.

As terras de trabalho, por sua vez, são formadas pelos terrenos de sequeiro (não irrigados), com medida de seis hectares, e pelos terrenos irrigados (ainda sem irrigação porque as águas do rio São Francisco não chegaram ao município) de um hectare de área, além de outras áreas de preservação ambiental. Cada família reassentada na Vila tem direito a um lote residencial, um lote de sequeiro e um lote irrigado.

Agora a gente vive num condominio, com regras para tudo. Foi como uma jovem senhora descreveu a nova forma de vida que passou a ter na vila Cacaré. Uma frase que alude à nova paisagem dos traçados regulares dos lotes e das ruas do setor residencial, bem como, às novas regras de uso da terra e de convivência comunitária, pois não se mora mais em Sítio, mas num condomínio. Não obstante, paisagens e regras vêm sendo reelaboradas no dia a dia dos seus moradores, delineando-se adaptações feitas ao novo lugar - a vila produtiva rural - edificado e regulamentado com dissonâncias em relação à vida e ao tempo do Sítio, que em certa medida parecem almejar reviver.

A modificação de alguns elementos arquitetônicos das casas de moradia é um exemplo dessas reelaborações, que começaram antes mesmo da finalização da construção da vila, quando os futuros moradores eram impedidos de adentrarem os canteiros de obras ${ }^{26}$. Isso se deu, por exemplo, na demanda exitosa para a modificação da estrutura do telhado das casas, que no projeto inicial constava ser de material metálico, mas acabou sendo modificado pela madeira, como eram as casas levadas ao chão nos Sítios.

Posteriormente, nos pouco mais de dois anos de moradia nas vilas, outras modificações vêm sendo realizadas pelos reassentados nas casas de morada. Merecem destaque as recorrentes obras de ampliação das cozinhas, como estratégias de transformação de uma casa estranha (exótica) num lugar

25 Até o início de 2019 o Ministério da Integração Nacional ainda não definiu as regras da futura utilização desses lotes de reserva. A expectativa é de que sejam atribuídos a novos núcleos familiares formados a partir da união conjugal de filhos de famílias assentadas, ou seja, utilizados como uma estratégia de acesso à terra diante de situações de crescimento populacional na vila.

26 Os futuros moradores tiveram conhecimento do projeto das casas a partir das várias reuniões de treinamento promovidas pelo Ministério da Integração Nacional a que foram obrigadas a participar como condição necessária para o reassentamento. 
familiar. Enquanto suas casas no Sítio possuíam cozinhas amplas, ou mesmo duas cozinhas, uma interna e outra nos fundos, nas casas originais da vila elas são tão ínfimas que não cabe nem mesmo uma mesa de comer. Perscrutando etnografias sobre casas camponesas, nota-se que a cozinha, normalmente ampla, figura nesses contextos como um lugar central, o fogo ou o coração da casa e da família que nela habita. Um lugar atribuído à mulher-esposa, que nesses contextos, aparece quase sempre como a responsável pela preparação da comida de todo o grupo familiar (HEREDIA, 1979; PINA-CABRAL, 1984).

Observa-se, ademais, outras modificações frequentes nas casas da vila Cacaré: a construção de alpendres (varandas), na frente e na lateral das casas, e de cômodos anexos. Alpendres que operam como lugares de passagem entre a área privativa dos moradores da casa, o dentro da casa, e a parte de fora, entendido como lugar público. E os cômodos anexos, construídos normalmente sem comunicação com o interior da casa, e utilizados como garagens, quartinhos para armazenamento de ferramentas e produtos agrícolas ou para a implementação de pequenos comércios como mercearias e bares (Fotografias 1 e 2). Por fim, e com menor incidência, porque obras dispendiosas, aparece a substituição das portas e janelas de ferro por congêneres de madeira, como havia nos Sítios ${ }^{27}$.

Figura 2 - Casa em construção na vila Cacaré

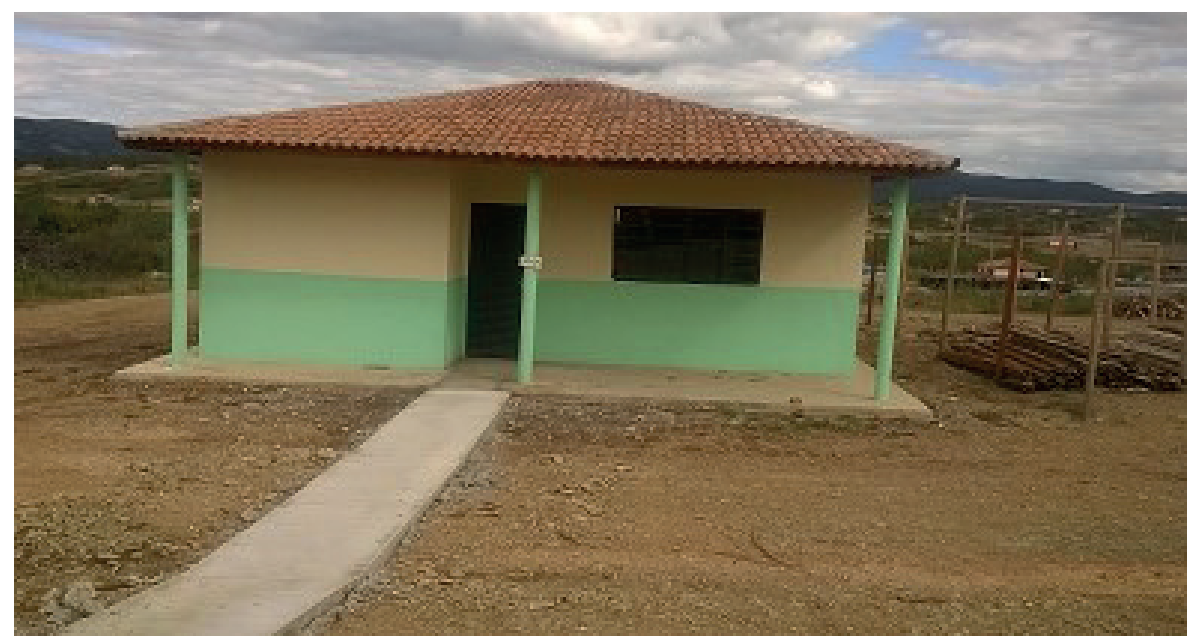

Fonte: Verena Nogueira (pesquisa de campo realizada em 2015).

27 A demanda pela substituição desses materiais data da época da construção das casas, mas diferentemente do êxito alcançado no material da base do telhado de madeira, as casas seguiram o projeto original no que tange a portas e janelas metálicas e sem persianas. 
Figura 3 - Casa na vila Cacaré após edificação de um cômodo anexo (mercadinho)

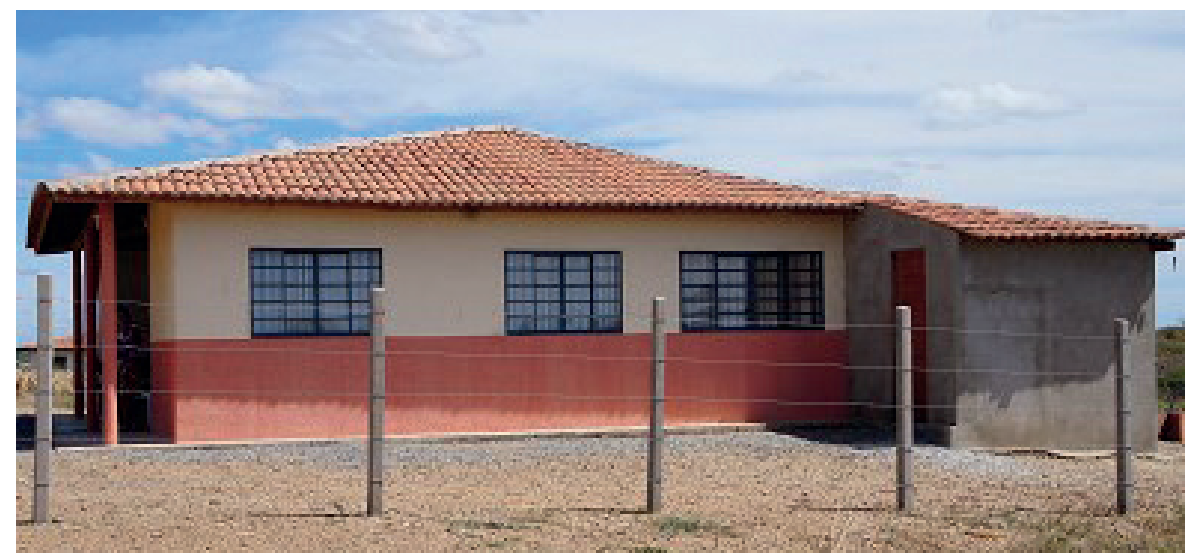

Fonte: Verena Nogueira (pesquisa de campo realizada em 2017).

Alguns lotes residenciais da vila Cacaré possuem novas casas de moradia ${ }^{28}$. Até setembro de 2018 ali já haviam sido construídas seis novas casas: uma para um viúvo que cedeu a casa recebida do governo para um filho que iria se casar; e outras cinco para novos casais, filhos e filhas de famílias reassentadas. Segundo a tradição camponesa, a constituição de novas famílias nucleares pressupõe a união conjugal de duas pessoas e a fixação de residência numa nova casa de morada (num novo chão de casa) separada da habitada por seu núcleo familiar de origem, embora muitas vezes na mesma terra familiar.

À propósito, o costume de construir uma nova casa para um novo casal no interior da terra dos pais de um dos noivos está relacionado às estratégias de reprodução do grupo familiar extenso, face à escassez de terras para as sucessivas partilhas requeridas pelo crescimento demográfico do grupo, de um lado, ou devido à carência de recursos financeiros para a compra de terras para seus descendentes, de outro. Dessa forma, os filhos costumeiramente se casam, têm suas casas de moradia (chão de casa) separadas da de seus pais, mas permanecem na mesma terra familiar (HEREDIA, 1979; GODOI, 1999; NOGUEIRA, 2010).

No primeiro ano de moradia nas vilas, as famílias puderam utilizar somente o lote residencial para plantio e criação de animais, pois, muito embora o lote de sequeiro já houvesse sido atribuído às famílias, elas não tinham permissão para utilizá-lo porque a licença ambiental ainda não havia sido concedida pelo órgão federal responsável pelo meio ambiente (IBAMA). Nos lotes residenciais cultivaram milho, feijão, capim e alguma fava, como faziam nos Sítios. Também

28 Em um lote residencial da vila Cacaré observou-se a edificação de uma quadra de futebol society e, num segundo, uma quadra particular de forró com um bar anexo. 
criaram galinhas, porcos, caprinos e plantaram algumas verduras e pés de frutas. No segundo ano após serem reassentadas, algumas famílias (poucas) botaram roça no lote de sequeiro, onde cultivaram milho, feijão e capim, assim como utilizaram a palhada do milho para os animais pastarem.

Numa configuração territorial camponesa tradicional, a roça é o lugar das lavouras de grãos e cereais e o quintal o lugar dos pés de fruta, da horta de verduras e ervas e da pequena criação (PEREIRA DE QUEIROZ, 1976; HEREDIA, 1979; GODOI, 1999; NOGUEIRA, 2010). Porém, diversamente dessa territorialidade camponesa clássica, em que as roças são dispostas em áreas separadas e distantes das casas de morada, na vila Cacaré as roças vêm sendo cultivadas ao redor das casas, nos próprios lotes residenciais, disputando lugar com o que nos Sítios era somente a área dos quintais. Uma sobreposição de lugares - roça e quintal que conforma uma nova territorialidade, no sentido da construção de um novo e diferente lugar de vida (território) para as famílias reassentadas.

Por outro lado, estamos diante de uma nova forma de organizar o território que pode desaparecer por causa da recente liberação do uso dos lotes de trabalho, lugares destinados às lavouras e à criação de gado fora dos quintais das casas de morada. Nessa hipotética situação, ademais, podemos aventar a configuração de uma organização socioterritorial semelhante à que havia nos Sítios, e mais próxima, portanto, de uma territorialidade camponesa clássica. Contudo, e independente das formas como as famílias organizam ou venham a organizar seu território no futuro, enfatizo a partir dessa situação empírica, o caráter processual da noção de territorialidade, que possibilita conferir plasticidade ao território que se encontra "em permanente conformação", e nunca como "uma construção definitivamente acabada" (GODOI, 2014, p. 444).

No que se refere ao trabalho agrícola nas vilas, observa-se que vem sendo realizado pelos membros de um mesmo núcleo familiar e moradores de um mesmo lote, não obstante serem recorrentes as ajudas de vizinhos e parentes, especialmente quando há poucas pessoas na família com idade e capacidade de trabalho. Uma forma de organização do trabalho análoga ao que havia nos Sítios desapropriados, assim como, encontrada em diversos contextos camponeses (PEREIRA DE QUEIROZ, 1976; GARCIA JÚNIOR, 1983; WOORTMANN, 1990). A ajuda mútua, por contraparte, denota obediência a uma regra de sociabilidade e condição para o pertencimento a um grupo de vizinhos e parentes, seja nos antigos Sítios ou na nova vida nas vilas.

No que tange ao trato dos animais de médio e grande porte, uma das regras condominiais da vila é a interdição da criação do gado solto. A criação deve acontecer dentro dos limites dos lotes residenciais ou nos lotes de sequeiro, ambos 
devidamente cercados. Ter gado no lote residencial é apenas uma modalidade em tempo parcial, pois a área é insuficiente para fornecer alimentação para o gado durante todo o ano. A criação no lote de sequeiro é ainda incipiente, pois a maioria deles ainda não dispõe de reservatório de água para os animais ${ }^{29}$. Diante dessas limitações para a atividade da criação de gado, alguns moradores vêm-se utilizando de estratégias como comprar o pasto, isto é, negociar a palhada de lotes vizinhos que não têm gado, transferir os animais parte do ano para outras terras, alugadas ou emprestadas fora da vila, ou soltá-los nas terras do governo.

Prosseguindo na descrição da vila Cacaré, nota-se que os lotes residenciais foram numerados e dispostos lado a lado nas ruas de terra. Para seus moradores, uma nova forma de organização do espaço físico com que precisam lidar para a nova vida em condominio ${ }^{30}$, como explicou uma moradora, ao diferenciar a divisão e a organização espacial da vila, mais próxima a um modelo ideal urbano, da do Sítio onde vivia até ser desapropriada. Porém, se de um lado se vislumbra um novo arranjo territorial e arquitetônico das vilas produtivas rurais, de outro, esse novo formato de organização espacial do espaço passa a ser vivido e reelaborado por seus moradores a partir do acionamento de conhecimentos e práticas territoriais trazidas dos Sítios, gerando como já explicitado acima, novas territorialidades.

Todas as casas da vila possuem um número visível num papel adesivo afixado em suas janelas frontais ${ }^{31}$. O conhecimento do número da casa e, principalmente, do número da casa dos vizinhos, passou a ser algo recorrente e mesmo esperado pelos moradores da vila. Era comum observar o fato de as pessoas sentirem orgulho ao me dizer que sabiam o número da casa de outro morador.

Diferente do que ocorre com os números das casas é a maneira de se referenciar as ruas de terra que margeiam as casas, pois muito embora na planta oficial da vila as ruas tenham recebido letras do alfabeto, esse código foi abortado e, em seu lugar, as famílias elegeram outras maneiras de referenciá-las. Um primeiro critério é a nomeação da rua pelo nome do Sítio de onde saiu a maioria dos seus atuais moradores, por exemplo, "rua de Santa Luzia". Outra forma de nomeação é pelo patronímico dos seus moradores, que normalmente também vieram de um mesmo Sítio ou de áreas avizinhadas, como rua do povo dos Afonso ou rua dos Carula. As ruas recebem o nome também em decorrência da atividade destacada de um de seus moradores como rua do Zé do Bode, pois ali o Zé cria

29 Ainda é limitada a presença de animais nos lotes de sequeiro, ocorrendo apenas nos lotes em seus proprietários conseguiram fazer um barreirinho (pequeno açude).

30 Relevante mencionar que na planta das vilas, a área residencial é denominada de "setor urbano".

31 Em algumas casas, conjuntamente ao adesivo afixado pelo governo, encontramos plaquinhas decorativas indicando o número das casas. Quase sempre elas possuem motivos religiosos, e foram adquiridas de vendedores ambulantes que transitam comerciando toda sorte de objetos. Note-se, ademais, que os usos dessas placas são mais uma intervenção dos moradores nas casas no sentido de lhe dar diferenciação e familiaridade. 
e vende bode, rua da borracharia, onde há uma borracharia, e assim por diante. Um quarto critério, ainda, referência a rua por sua mera localização física: rua da entrada, rua da praça, rua da caixa d'água.

Nessas parcas e pontuais intervenções dos reassentados nas vilas, como as modificações arquitetônicas nas casas, as formas de referenciar os lugares da vila e as (nem tão) novas práticas agrícolas desenvolvidas nos lotes residenciais, vêm se revelando tentativas êmicas de transformar um vaz̧io só que encontraram em algo mais familiar e semelhante ao Sítio e à vida que tinham antes da desapropriação. Uma familiaridade, aliás, que podemos aproximar da noção de Topofilia, proposta pelo geógrafo indiano Yu-Fu Tuan (2012), entendida como o elo afetivo entre as pessoas e o lugar ou ambiente físico.

\section{À GUISA DE CONCLUS̃̃O}

Este artigo procurou refletir acerca do processo de territorialização a que vêm sendo submetidos os sitiantes do município de São José de Piranhas em decorrência do projeto de transposição do rio São Francisco. O foco analítico recaiu nas famílias reassentadas numa das quatro vilas produtivas rurais construídas no município, a vila produtiva Cacaré, habitada por um grupo de cento e trinta famílias.

O processo de reassentamento implicou num deslocamento entre áreas geograficamente próximas e com características ambientais semelhantes. Um fato que em certa medida traz continuidades, como explicou uma reassentada ao apontar para o outro lado de uma estrada de terra da vila e dizer eu morava ali, aqui mesmo; mas também envolve rupturas, reveladas na sequência da explicação quando adverte, mas agora [na vila] é tudo diferente. Portanto, podemos sugerir estar diante de um processo de deslocamento espacial que submeteu as famílias reassentadas numa nova paisagem e a novas regras de trabalho, moradia e convivência.

Uma vez nas vilas, observou-se como as famílias reassentadas, no escopo de lidar com essas mudanças e refazer, em certa medida, o modo de vida anterior que tinham nos Sítios, vêm realizando arranjos e modificações socioterritoriais. Diria mesmo que essas ações denotam continuidades na forma de praticar o território, como na maneira de morar, de plantar, de conviver e de pensar o futuro de seus filhos. Exemplos disso podem ser percebidos na modificação das casas de morada, como tentativas de transformar esse lugar físico em algo mais parecido com as casas dos Sítios, ou nas construções de novas casas nos lotes residenciais, para os novos núcleos familiares gerados pelo casamento dos filhos e filhas dos atuais moradores, numa continuidade com um costume trazido 
do Sítio camponês, de agrupar, em torno da casa do chefe da parentela, seus descendentes. Também foi apresentada a retomada de atividades agropastoris que costumavam realizar nos Sítios de origem, como as lavouras de milho, feijão e fava, além da criação de alguns animais.

Em suma, procurou-se analisar um processo de desterritorialização que envolveu, de um lado, uma ação violenta do Estado brasileiro que, para levar adiante as obras do projeto de transposição do rio São Francisco, forçou a saída das famílias de seus territórios tradicionais, os Sítios, submetendo-as a viver num novo lugar, as vilas produtivas rurais, configurado sob novas paisagens e novas regras de organização socioterritorial. E, de outro lado, um processo de reterritorialização que inclui as não menos importantes reelaborações pelas famílias reassentadas na construção do novo território nas vilas.

\section{REFERÊNCIAS}

ALMEIDA, A. W. B; SOUZA, R. M. (org.). Terras de faxinais. Manaus: Editora da Universidade do Estado do Amazonas, UEA, 2009.

BRASIL. Lei $\mathbf{n}^{\circ}$ 4.214, de 2 de março de 1963. Dispõe sobre o Estatuto do Trabalhador Rural. Brasilia: Casa Civil, [1963]. Disponível em: https://www. planalto.gov.br/ccivil_03/leis/1950-1969/14214.htm. Acesso em: 19 nov. 2019.

CAMARGO, C. S. A água e seus fluxos: ação coletiva, conflitos territoriais e povos indígenas na transposição do rio São Francisco. 2017. 338 f. Tese (Doutorado em Ciências Sociais) - Instituto de Filosofia e Ciências Humanas, Universidade Estadual de Campinas, Campinas, 2017.

CARVALHO, F. P. Fundo de pasto: territorialidade e uso comum. Ruris, Campinas, v. 10, n. 2, p. 47-73, set. 2016.

COVER, M. O "tranco da roça" e a "vida no barraco": um estudo sobre trabalhadores migrantes no setor do agronegócio canavieiro. João Pessoa: Editora da UFPB, 2011.

GARCIA JÚNIOR, A. Terra de trabalho: trabalho familiar de pequenos produtores. Rio de Janeiro: Paz e Terra, 1983.

GODOI, E. P. O trabalho da memória: cotidiano e história no sertão do Piauí. Campinas: Editora da UNICAMP, 1999.

GODOI, E. P. Territorialidade. In: SANSONE, L.; FURTADO, C. A. (org.). Dicionário crítico das Ciências Sociais dos países de fala oficial portuguesa. Salvador: EDUFBA, 2014. p. 443-452. 
GONÇALVES, C. D. B. Impactos, conflitos e tensões do projeto de integração do rio São Francisco no município de São José de Piranhas, PB. 2014. 156 f. Dissertação (Mestrado em Desenvolvimento Regional) - Programa de Pós-graduação em Desenvolvimento Regional, Universidade Estadual da Paraíba, Campina Grande, 2014.

HAESBAERT, R. O mito da desterritorialização: do fim dos territórios à multiterritorialidade. Rio de Janeiro: Bertrand Brasil, 2004.

HEREDIA, B. A morada da vida. Rio de Janeiro: Paz e Terra, 1979.

INSTITUTO DE PESQUISA ECONÔMICA APLICADA. Brasil em desenvolvimento: Estado, planejamento e políticas públicas. Brasília: IPEA, 2010.

LIMA, L. C. Além das águas, a discussão no nordeste do rio São Francisco.

Revista do Departamento de Geografia, São Paulo, v. 17, p. 94-100, 2005.

MENEZES, M. A. Da Paraíba pra São Paulo e de São Paulo pra Paraíba. 1985. 176 f. Dissertação (Mestrado em Sociologia Rural) - Programa de Pós-graduação em Sociologia Rural, Universidade Federal da Paraíba, João Pessoa, 1985.

NASCIMENTO, G. A. Efeitos socioculturais da transposição do rio São Francisco em comunidades rurais: a experiência de São José de Piranhas no sertão paraibano. 2018. 117 f. Dissertação (Mestrado em Antropologia) Programa de Pós-graduação em Antropologia, Universidade Federal da Paraíba, João Pessoa, 2018.

NOGUEIRA, V. S. “Sair pelo mundo". A conformação de uma territorialidade camponesa. 2010. 279 f. Tese (Doutorado em Antropologia) - Instituto de Filosofia e Ciências Humanas, Universidade Estadual de Campinas, Campinas, 2010.

NOGUEIRA, V. S. Do "Sítio" à vila produtiva rural: os percursos de famílias rurais desapropriadas pelas obras de transposição do rio São Francisco, no Brasil. In: REUNIÃO DE ANTROPOLOGIA DO MERCOSUL, 11., 2015, Montevidéu. Anais [...]. Montevidéu: Universidad de la Republica, 2015. Disponível em: http://xiram.com.uy/actas-del-congreso/grupos-de-trabajo/ ponencias-grupo-de-trabajo-82. Acesso em: 05 nov. 2018.

NOGUEIRA, V. S. Vilas produtivas rurais e "Terra do Governo": reassentamento de famílias rurais atingidas por obras da transposição do rio São Francisco. In: REUNIÃO DE ANTROPOLOGIA, 31., 2018, Brasília. Anais [...]. Brasília: Universidade de Brasília, 2018. Disponível em: http://www.evento. abant.org.br/rba/31RBA/files/1541461554_ARQUIVO_18_RBA_paper_ VerenaSevaNogueira.pdf/. Acesso em: 04 abril 2019. ISBN: 978-85-87942-61-6. 
OLIVEIRA, J. P. Uma etnologia dos índios misturados? Situação colonial, terrritorialização e fluxos culturais In: OLIVEIRA, J. P. O nascimento do Brasil e outros ensaios: "pacificação, regime tutelar e formação de alteridades. Rio de Janeiro: Contra Capa, 2016. p. 193-228.

PALMEIRA, M. Casa e trabalho: nota sobre as relações sociais na plantation tradicional. Contraponto, Rio de Janeiro, Ano II, n. 2, p. 101-114, 1977.

PEREIRA DE QUEIROZ, M. I. O campesinato brasileiro. Rio de Janeiro: Vozes, 1976.

PINA-CABRAL, J. Comentários críticos sobre a casa e a família no Alto Minho rural. Análise Social, Lisboa, v. XX (81-82), n. 2-3, p. 263-284, 1984.

PINA-CABRAL, J. Agnatas, vizinhos e amigos: variantes da vicinalidade em África, Europa e América. Revista de Antropologia, São Paulo, v. 57, n. 2, p. 23-46, dez. 2014. Disponível em: http://www.periodicos.usp.br/ra/article/ view/89107. Acesso em: 22 out. 2017.

RAFFESTIN, C. Por uma geografia do poder. São Paulo: Ática, 1983.

SAHLINS, M. Sociedades tribais. Rio de Janeiro: Zahar, 1970.

SIGAUD, L. Implicações sociais da política do setor elétrico. In: SANTOS, L.; ANDRADE, L. (org.). As hidrelétricas do Xingu e os povos indígenas. São Paulo: CPI, 1988. p. 103-110.

SIGAUD, L. Armadilhas da honra e do perdão: usos sociais do direito na mata pernambucana. Mana, Rio de Janeiro, n. 10, v. 1, p. 131-163, 2004.

TEIXEIRA, J. L. Vivendo encangado: parentesco, mobilidade e proximidade entre os moradores do Sertão de Inhamus (CE). In: REUNIÃO DA ASSOCIAÇÃO BRASILEIRA DE ANTROPOLOGIA, 29., 2014, Natal. Anais [...]. Brasília: Kiron, 2014, p. 1-20.

TUAN, Y-F. Topofilia: um estudo da percepção, atitudes e valores do meio ambiente. Londrina: Eduel, 2012.

WOORTMANN, E. Herdeiros, parentes e compadres: colonos do Sul e sitiantes do Nordeste. São Paulo: HUCITEC; Brasília: Editora Universidade de Brasília, 1995.

WOORTMANN, K. "Com parente não se neguceia": o campesinato como ordem moral. Anuário Antropológico, Brasília, n. 87, p. 11-73, 1990. 